University of Windsor

Scholarship at UWindsor

6-11-2015

\title{
Efficacy of a Sexual Assault Resistance Program for University Women
}

Charlene Y. Senn

University of Windsor

Misha Eliasziw

Paula C. Barata

Wilfreda E. Thurston

Ian R. Newby-Clark

See next page for additional authors

Follow this and additional works at: https://scholar.uwindsor.ca/psychologypub

Part of the Psychology Commons

\section{Recommended Citation}

Senn, Charlene Y.; Eliasziw, Misha; Barata, Paula C.; Thurston, Wilfreda E.; Newby-Clark, lan R.; Radtke, H. Lorraine; and Hobden, Karen L.. (2015). Efficacy of a Sexual Assault Resistance Program for University Women. New England Journal of Medicine, 372 (2326), 2335.

https://scholar.uwindsor.ca/psychologypub/42

This Article is brought to you for free and open access by the Department of Psychology at Scholarship at UWindsor. It has been accepted for inclusion in Psychology Publications by an authorized administrator of Scholarship at UWindsor. For more information, please contact scholarship@uwindsor.ca. 
Authors

Charlene Y. Senn, Misha Eliasziw, Paula C. Barata, Wilfreda E. Thurston, Ian R. Newby-Clark, H. Lorraine Radtke, and Karen L. Hobden 


\title{
Efficacy of a Sexual Assault Resistance Program for University Women
}

\author{
Charlene Y. Senn, Ph.D., Misha Eliasziw, Ph.D., Paula C. Barata, Ph.D., \\ Wilfreda E. Thurston, Ph.D., Ian R. Newby-Clark, Ph.D., H. Lorraine Radtke, Ph.D., \\ and Karen L. Hobden, Ph.D.
}

From the Department of Psychology and Women's and Gender Studies Program, University of Windsor, Windsor, ON (C.Y.S., K.L.H.), the Departments of Community Health Sciences (M.E., W.E.T.) Ecosystem and Public Health (W.E.T.) and Psychology (H.L.R.), University of Calgary, Calgary, AB, and the Department of Psychology, University of Guelph, Guelph, ON (P.C.B., I.R.N.-C.) - all in Canada; and the Department of Public Health and Community Medicine, Tufts University, Boston (M.E.). Address reprint requests to Dr. Senn at the Department of Psychology, University of Windsor, 401 Sunset Ave., Windsor, ON N9B 3P4, Canada, or at csenn@uwindsor.ca.

N EnglJ Med 2015;372:2326-35. DOI: 10.1056/NEJMsa1411131

Copyright @ 2015 Massachusetts Medical Society.
ABSTRACT

\section{BACKGROUND}

Young women attending university are at substantial risk for being sexually assaulted, primarily by male acquaintances, but effective strategies to reduce this risk remain elusive.

\section{METHODS}

We randomly assigned first-year female students at three universities in Canada to the Enhanced Assess, Acknowledge, Act Sexual Assault Resistance program (resistance group) or to a session providing access to brochures on sexual assault, as was common university practice (control group). The resistance program consists of four 3-hour units in which information is provided and skills are taught and practiced, with the goal of being able to assess risk from acquaintances, overcome emotional barriers in acknowledging danger, and engage in effective verbal and physical self-defense. The primary outcome was completed rape, as measured by the Sexual Experiences Survey-Short Form Victimization, during 1 year of follow-up.

RESULTS

A total of 451 women were assigned to the resistance group and 442 women to the control group. Of the women assigned to the resistance group, 91\% attended at least three of the four units. The 1-year risk of completed rape was significantly lower in the resistance group than in the control group $(5.2 \%$ vs. $9.8 \%$; relative risk reduction, $46.3 \%$ [95\% confidence interval, 6.8 to 69.1 ]; $\mathrm{P}=0.02$ ). The 1-year risk of attempted rape was also significantly lower in the resistance group (3.4\% vs. $9.3 \%, \mathrm{P}<0.001)$.

\section{CONCLUSIONS}

A rigorously designed and executed sexual assault resistance program was successful in decreasing the occurrence of rape, attempted rape, and other forms of victimization among first-year university women. (Funded by the Canadian Institutes of Health Research and the University of Windsor; SARE ClinicalTrials.gov number, NCT01338428.) 
Yenas OUNG WOMEN ATTENDING UNIVERSITY ${ }^{1,2}$ face a substantial risk of being sexually assaulted. The incidence of sexual assault is estimated to be between $20 \%$ and $25 \%$ over a period of 4 years and to be highest during the first 2 years. ${ }^{3,4}$ Being sexually assaulted can result in post-traumatic stress disorder, depression, alcohol use, and decreased safer-sex practices, among other negative health outcomes. ${ }^{5}$ In addition to the specific health consequences for the woman, ${ }^{6}$ the social and financial costs to society are also high.,8

With the renewal of the Violence Against Women Act ${ }^{9}$ and establishment of a White House task force ${ }^{10}$ in the United States and increasing public awareness of this problem in Canada, ${ }^{11}$ universities face heightened pressure to educate students about sexual assault. However, most campuses use programs that have never been formally evaluated or have not proved to be effective in reducing the incidence of sexual assault. ${ }^{12}$ For example, the bystander approach is designed to increase men's and women's willingness to intervene when they encounter rapesupportive attitudes or behaviors, thereby changing the campus climate. ${ }^{13}$ Men are approached as allies and not as potential perpetrators. Studies generally have not assessed sexual assault rates after such training, ${ }^{14}$ although one intervention using the bystander approach with the addition of content designed to shift the social norms of the specific peer group (residence hall) showed a reduction in men's self-reported sexual aggression. ${ }^{15}$ Other targeted programs for men and for women that have been evaluated for sexual assault outcomes ${ }^{13}$ have been disappointing, including interventions designed to decrease male perpetration of sexual assault. ${ }^{16}$

Workshops designed to help women resist sexual assault or reduce their risk have had inconsistent effects. Two studies showed shortterm benefit, which in one study was limited to women who had had no previous victimiza$\operatorname{tion}^{17,18}$; other studies showed no clear benefits at 2, 4, or 6 months, even with "booster" sessions (i.e., sessions that review or expand on content to maintain or improve effects). ${ }^{19-21}$ All but one study was conducted at a single site, two used grouplevel randomization, ${ }^{17,19}$ and the one with the longest follow-up had a high rate of attrition. ${ }^{21}$
The aim of the current trial was to assess whether a new, four-unit, small-group sexual assault resistance program, ${ }^{22}$ as compared with access to brochures on sexual assault, could reduce the 1-year incidence of completed rape among first-year female students at three universities.

\section{METHODS}

\section{ENROLLMENT AND RANDOMIZATION}

The Sexual Assault Resistance Education (SARE) Trial was approved by the ethics boards at the Universities of Windsor, Guelph, and Calgary. The full study protocol and the baseline characteristics and sexual assault histories have been published previously ${ }^{4,22}$; the study protocol is also available with the full text of this article at NEJM.org. The first author assumes responsibility for the fidelity of the report to the protocol and the accuracy and completeness of the data.

In brief, this open-label, randomized, controlled trial enrolled first-year female students, 17 to 24 years of age, at one large university in western Canada and two midsized universities in central Canada, from September 2011 to February 2013. To be eligible for the trial, students had to be able to attend one of four scheduled sets of intervention sessions during the semester in which they enrolled in the study. A total of $69.4 \%$ of the participants were recruited through e-mail messages and telephone calls to first-year female students who were registered in the research participant pools of psychology departments; approximately $70 \%$ of students on campus register for psychology courses and are thereby included in these pools. Other participants were recruited through posters or flyers around campus, e-mail messages forwarded by professors, and presentations in classes and at student events. A research assistant explained the study before scheduling a participant's baseline session. At the baseline session, participants completed a computerized survey, underwent randomization, and immediately attended their first resistance session or a control session. Randomization was performed in permuted blocks of two with the use of the online tool Randomize.net, with stratification according to site. All the participants gave written informed consent. 


\section{INTERVENTIONS}

The Enhanced Assess, Acknowledge, Act Sexual Assault Resistance program consisted of four 3-hour units that involved information-providing games, mini-lectures, facilitated discussion, and application and practice activities. The first author developed, revised, and pilot-tested the program between 2005 and 2011..$^{23,24}$ The names (Assess, Acknowledge, and Act) and content of the first three units were based on recommendations by Rozee and Koss for a resistance program for women. ${ }^{25}$ These authors drew heavily on the work of Ullman regarding successful rape self-defense strategies ${ }^{26}$ and on Nurius and Norris's "cognitive ecological" model, ${ }^{27}$ which provided a theoretical framework for the environmental and psychological factors that affect women's responses to sexual assault. The fourth unit (Sexuality and Relationships) adapted content from the Our Whole Lives sexuality-education curricula. ${ }^{28,29}$ Participants assigned to the resistance group could choose to attend sessions for all the units in one weekend (two units each day) or for one unit per week for 4 weeks.

Unit 1 (Assess) focused on improving women's assessment of the risk of sexual assault by male acquaintances and developing problemsolving strategies to reduce perpetrator advantages. Unit 2 (Acknowledge) assisted women to more quickly acknowledge the danger in situations that have turned coercive, explore ways to overcome emotional barriers to resisting the unwanted sexual behaviors of men who were known to them, and practice resisting verbal coercion. Unit 3 (Act) offered instruction about and practice of effective options for resistance; this unit included 2 hours of self-defense training based on Wen-Do. ${ }^{30}$ The unit focused on common sexual assault situations involving acquaintances and defense against attackers who were larger than the woman. Unit 4 (Sexuality and Relationships) aimed to integrate content from the previous units into participants' sexual lives by providing sexual information, including the slang and scientific terms for a wide range of possible sexual activities beyond intercourse and health and safer-sex practices, and a context to explore their sexual attitudes, values, and desires and to develop strategies for sexual communication.

A detailed manual provided instructions for facilitators (see the Supplementary Appendix, available at NEJM.org). Initially, a 10-day training period, which included training in self-defense, was conducted for facilitators. In year 2, because most facilitators were experienced, the training period was shortened to 1 week.

In the control sessions, brochures on sexual assault were displayed; this mimicked common university practice of having brochures available in campus clinics and counseling centers. The selection of brochures was campus-specific; however, the content was similar across sites and included general information on sexual assault and post-rape legal and medical advice (see the Supplementary Appendix). A research assistant informed participants about the brochures and invited them to take them and read them; this assistant also offered to answer questions in the group session, which was scheduled to last 15 minutes, or privately afterward.

All resistance and control sessions were audiorecorded to assess fidelity to the interventions and staff adherence to the procedures and content. One quarter of the recordings from both groups, stratified according to facilitator or research assistant and semester, were randomly selected and scored according to checklists developed from the operations manuals. The mean scores for fidelity to the intervention were 94\% (range, 81 to 100) for the resistance sessions and $86 \%$ (range, 75 to 100) for the control sessions.

\section{DATA COLLECTION}

All the participants completed in-person computerized surveys at baseline and 1 week after completion of the intervention (control participants were matched to the same interval but participated in only one session) and offsite Web-based surveys at 6 months and 12 months. To minimize attrition, participants in both groups were contacted by telephone, text, or e-mail at each time point, with up to seven attempts at contact made at each time point. Incentives were provided for completing the baseline and postintervention surveys (psychology-course bonus credit and entry in a \$300 lottery) and the followup surveys ( $\$ 30$ gift cards). To retain participants in the resistance group during their multiple sessions, additional incentives (small gifts and tickets for two, $\$ 25$, end-of-session lotteries) 
were used. Women were considered to be lost to follow-up if they did not complete the survey at 12 months.

\section{OUTCOME MEASURES}

Information on sexual victimization was collected with the use of the Sexual Experiences Survey-Short Form Victimization (SES-SFV). ${ }^{31}$ The SES-SFV, a revision of the original 1982 SES, ${ }^{32}$ is the most widely used measure in sexual assault research and has high reliability and validity. ${ }^{33}$ Its strength is that it does not require correct labeling of sexual assault by participants but assesses how often particular experiences that legally constitute sexual assault (in Canada) and rape (in the United States) have occurred. For example, one item on the survey reads, "A man put his penis into my vagina, or inserted fingers or objects without my consent by using force, for example holding me down with his body weight, pinning my arms, or having a weapon."

All experiences reported during 12 months of follow-up were classified into one of five sexual victimization categories: completed rape, attempted rape, coercion, attempted coercion, or nonconsensual sexual contact. The primary outcome was completed rape; other outcomes were prespecified as tertiary. (Secondary outcomes were psychological variables that were expected to mediate the effects of the intervention and are not included here.) Completed rape (oral, vaginal, or anal penetration) and nonconsensual sexual contact (nonpenetrative) were defined as nonconsensual sexual acts in which the perpetrator used threats, force, or drug or alcohol incapacitation. Coercion was considered to have occurred when perpetrators used pressure or manipulation (e.g., "threatening to end the relationship" or "continually verbally pressuring me") to induce compliance in nonconsensual penetrative sexual acts. Attempted rape and attempted coercion were occasions in which the perpetrator tried to engage in the behavior but was not successful. For completed and attempted rapes, participants recorded the dates of occurrence.

Study-group cross-contamination was measured on follow-up surveys in which participants were asked whether they knew anyone in the other randomized group and, if so, what they shared with (or were told by) that person.

\section{STATISTICAL ANALYSIS}

Outcomes were assessed in the modified intention-to-treat population, which included all eligible participants who completed one or more postrandomization survey. The primary analysis compared the incidence (first occurrence) of completed rape between the control group and the resistance group with the use of KaplanMeier failure curves (indicating the cumulative percentage of completed rapes among women in the respective groups) and the log-rank test. To account for the correlation among observations within group sessions, variance estimates were appropriately inflated ${ }^{34}$ for within-session clustering with the use of estimates of the design effect. The benefit of the resistance program was described in terms of relative risk reductions and the number of women who would need to participate in the program to prevent one additional completed rape from occurring within 1 year after participation. Because researchers have speculated that rates of attempted rape might be increased by resistance training, ${ }^{21}$ the incidence of attempted rape was also assessed.

In other modified intention-to-treat analyses, the incidences of coercion, attempted coercion, and nonconsensual sexual contact were compared between the control group and the resistance group with the use of discrete-time survival analyses that used a complementary log-log regression model, ${ }^{35}$ in which the variance estimates for within-session clustering were also inflated. ${ }^{36}$

Two prespecified subgroup analyses were performed to assess whether the resistance program had a similar effect regardless of prior rape victimization and program timing (i.e., weekend vs. weekday sessions); tests for interaction were performed with the use of a Cox proportionalhazards regression model. All $\mathrm{P}$ values were two-tailed, and P values of less than 0.05 were considered to indicate statistical significance. All statistical analyses were performed with the use of SAS software, version 9.3 (SAS Institute).

\section{RESULTS}

\section{PARTICIPANTS}

Of the 916 women who underwent randomization, 17 were found on postrandomization review not to have met eligibility criteria, and 6 did 


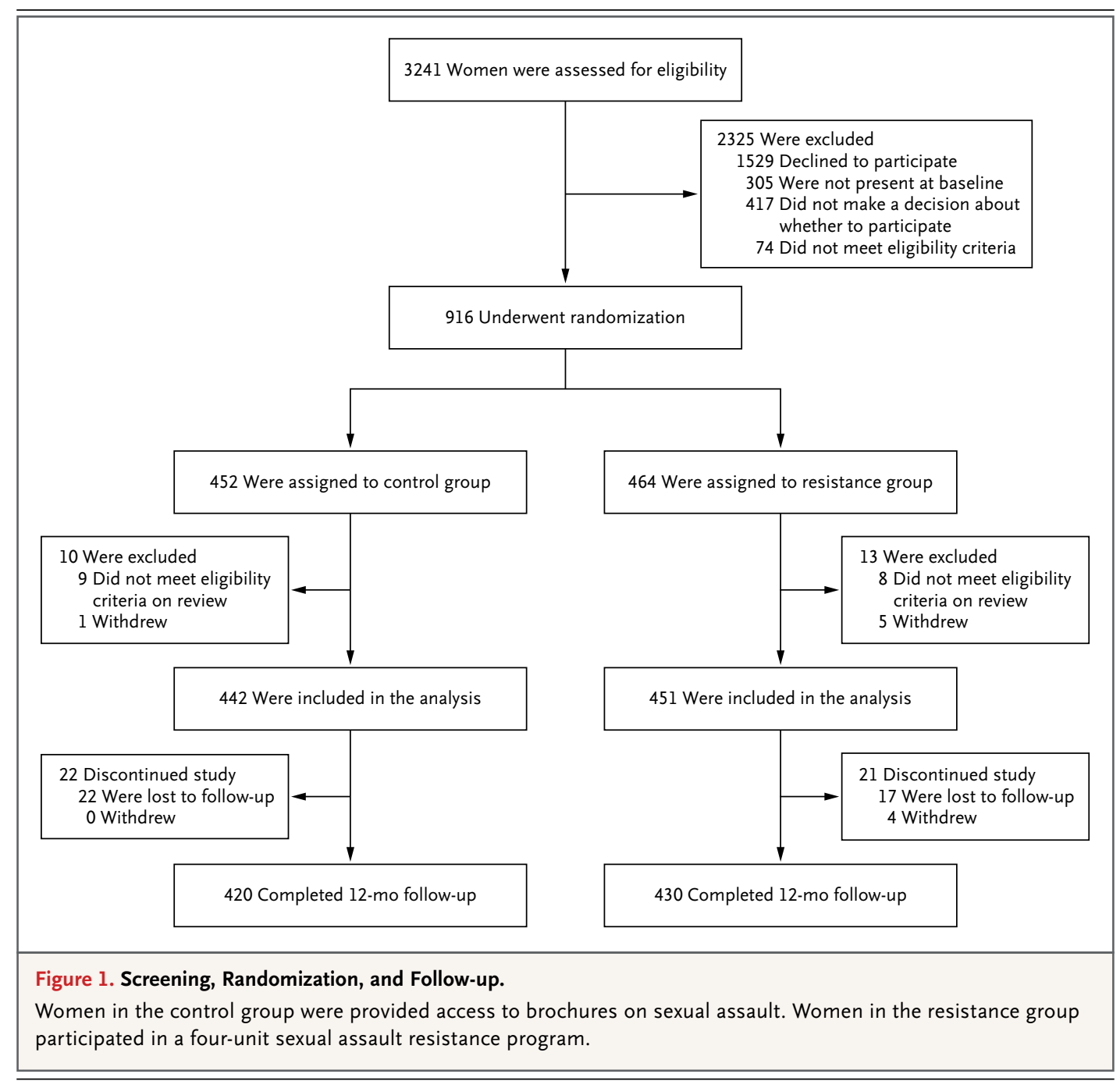

not complete any postrandomization follow-up surveys. Therefore, 893 women were included in the analyses (Fig. 1). A total of 442 women were assigned to the control group and attended 1 of the 45 control sessions that were held during the course of the study (mean number of women per session, 9.8; range, 3 to 21). A total of 451 women were assigned to the resistance group and attended 1 of the 48 four-unit resistance sessions that were held during the course of the study (mean number of women per session, 9.4; range, 3 to 23). The design effect for the completed-rape outcome was estimated to be 1.25 , calculated according to an overall mean of 9.6 women per session and a corresponding withinsession correlation of 0.029 among observations.
The two groups were well-balanced with respect to baseline characteristics (Table 1).

Adherence in the resistance group was high (91\%), with $95 \%$ and $88 \%$ of the participants attending three or more units during weekend and weekday sessions, respectively. The mean followup was 11.6 months in both groups; $5.0 \%$ of the participants were lost to follow-up in the control group and $4.7 \%$ were lost to follow-up or withdrew from the study in the resistance group. There were no crossovers between groups, and cross-contamination was low: $14.5 \%$ of the participants in the control group and $10.4 \%$ of the participants in the resistance group shared facts or skills learned in their group with participants in the other group. 


\begin{tabular}{|c|c|c|}
\hline Characteristic & $\begin{array}{l}\text { Control Group } \\
(\mathrm{N}=442)\end{array}$ & $\begin{array}{l}\text { Resistance Group } \\
\qquad(N=451)\end{array}$ \\
\hline Age $-y r$ & $18.5 \pm 1.2$ & $18.5 \pm 1.2$ \\
\hline White race or European descent — no. (\%) $†$ & $326(73.8)$ & $325(72.1)$ \\
\hline Heterosexual identity — no. (\%) & $405(91.6)$ & $414(91.8)$ \\
\hline Living in a university residence - no. (\%) & $240(54.3)$ & $243(53.9)$ \\
\hline Sexually active - no. (\%) & $271(61.3)$ & $281(62.3)$ \\
\hline Currently involved in a romantic relationship - no. (\%) & $195(44.1)$ & $205(45.5)$ \\
\hline Currently involved in a sexual relationship — no. (\%) & $202(45.7)$ & $202(44.8)$ \\
\hline Previous sexual assault education — no. (\%) & $19(4.3)$ & $17(3.8)$ \\
\hline Previous self-defense training - no. (\%) & $143(32.4)$ & $153(33.9)$ \\
\hline \multicolumn{3}{|l|}{ Sexual victimization since 14 yr of age - no. $(\%) \ddagger$} \\
\hline Completed rape & $105(23.8)$ & $103(22.8)$ \\
\hline Attempted rape & $130(29.4)$ & $115(25.5)$ \\
\hline Coercion & $101(22.9)$ & $97(21.5)$ \\
\hline Attempted coercion & $147(33.3)$ & $125(27.7)$ \\
\hline Nonconsensual sexual contact & $240(54.3)$ & $210(46.6)$ \\
\hline Recruited through psychology-research systems — no. (\%) & $312(69.2)$ & $308(69.7)$ \\
\hline Recruited in fall semester - no. (\%) & $259(58.6)$ & $257(57.0)$ \\
\hline Attended weekend sessions - no. (\%) & $151(34.2)$ & $165(36.6)$ \\
\hline \multicolumn{3}{|c|}{$\begin{array}{l}\text { Plus-minus values are means } \pm S D \text {. The only significant difference between groups was for nonconsensual sexual con- } \\
\text { tact }(\mathrm{P}=0.02) \text {. } \\
\text { Race or ethnic group was self-reported. } \\
\text { Completed rape (oral, vaginal, or anal penetration) and nonconsensual sexual contact (nonpenetrative) were defined a } \\
\text { nonconsensual sexual acts in which the perpetrator used threats, force, or drug or alcohol incapacitation. Coercion was } \\
\text { considered to have occurred when perpetrators used pressure or manipulation (e.g., "threatening to end the relation- } \\
\text { ship" or "continually verbally pressuring me") to induce compliance in nonconsensual penetrative sexual acts. } \\
\text { Attempted rape and attempted coercion were occasions in which the perpetrator tried to engage in the behavior but } \\
\text { was not successful. }\end{array}$} \\
\hline
\end{tabular}

\section{OUTCOMES}

The 1-year risk of completed rape was significantly lower in the resistance group than in the control group $(5.2 \%$ vs. $9.8 \%$; relative risk reduction, $46.3 \%$; $95 \%$ confidence interval [CI], 6.8 to 69.1; $\mathrm{P}=0.02$ ), indicating that only 22 women would need to take the program in order to prevent one additional rape from occurring within 1 year after participation (Table 2). The benefit of the resistance program occurred early, and its efficacy was sustained throughout the 1-year follow-up period (Fig. 2A). The program also reduced the incidence of attempted rape $(3.4 \%$ in the resistance group vs. $9.3 \%$ in the control group; relative risk reduction, 63.2\%; $\mathrm{P}<0.001$ ) (Table 2 and Fig. 2B). Incidences of nonconsen- sual sexual contact and attempted coercion were lower in the resistance group than in the control group, but there was no significant reduction in coercion in the resistance group (Table 2).

\section{SUBGROUP ANALYSES}

The 1-year risk of completed rape in the control group was nearly four times as high among previously victimized women as among women with no history of victimization ( $22.8 \%$ vs. $5.8 \%$ ) (Table 3). Despite the elevated risk among previously victimized women, the resistance group had a lower 1-year risk of completed rape than the control group (relative risk reduction, 25.1\%). The effect of the intervention did not vary significantly according to prior history of rape 


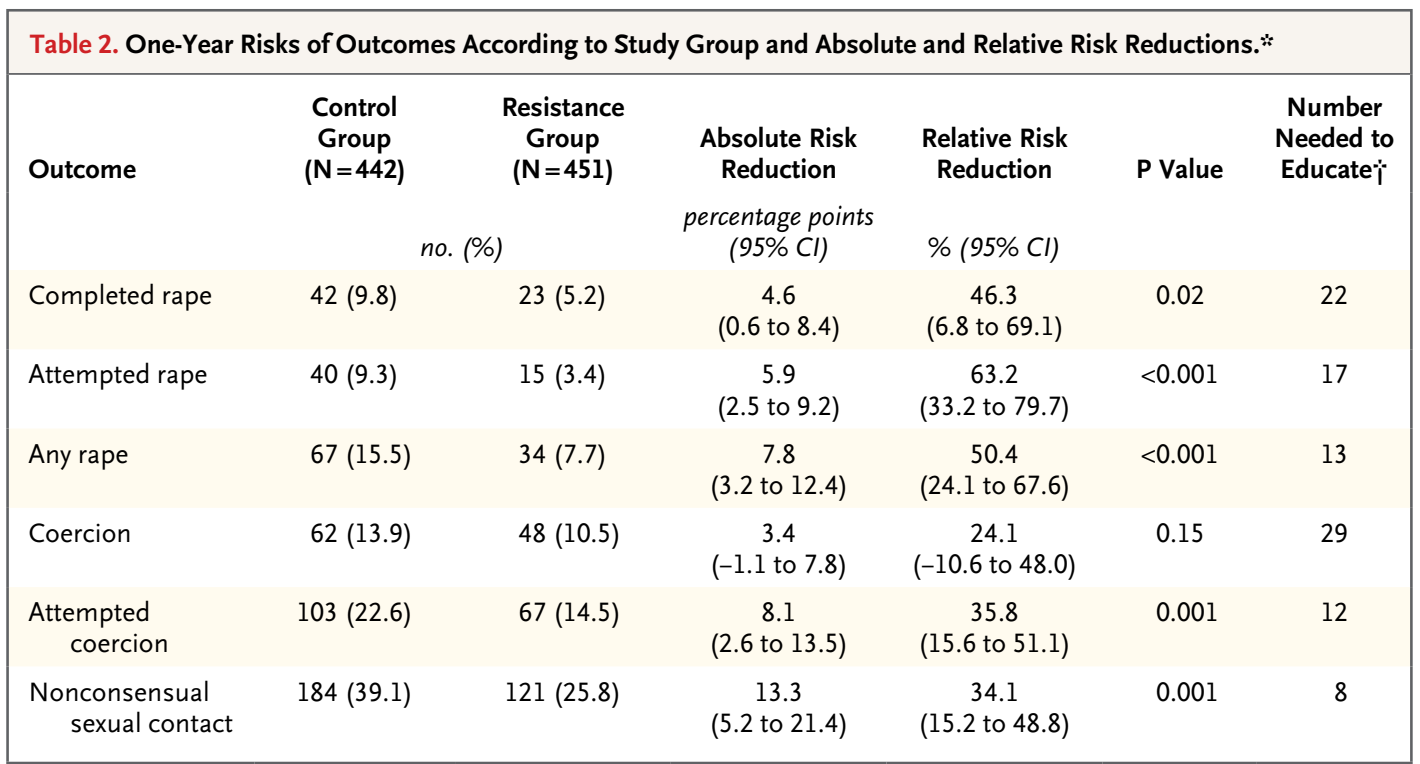

* Risk estimates, absolute risk reductions, and relative risk reductions were calculated from Kaplan-Meier failure curves (completed rape, attempted rape, and any rape) and from complementary log-log regression models (coercion, attempted coercion, and nonconsensual sexual contact), with variance inflation for within-session clustering. The analyses counted the first of each type of outcome during the 1-year follow-up period; therefore, women could have multiple outcomes during a single encounter or different encounters.

$\dagger$ The number needed to educate was the number of women who would need to participate in the resistance program to prevent one additional instance of the outcome from occurring within 1 year after participation. It was calculated as $1 \div$ absolute risk reduction expressed as a decimal.

( $\mathrm{P}=0.13$ for interaction) or according to whether programs were on weekends or weekdays $(\mathrm{P}=0.32$ for interaction) (Table 3).

\section{DISCUSSION}

In this randomized, controlled trial, the risk of completed rape (the primary outcome) was significantly lower over a period of 1 year among first-year university women who participated in a sexual assault resistance program than among those who were provided access to brochures on sexual assault. These results contrast with previous reports of the limited effectiveness of other interventions for women. ${ }^{17-21}$ An early version of one program reduced the risk of completed rape after 9 weeks of follow-up only among women with no history of victimization. ${ }^{17}$ In three of four subsequent studies assessing modified programs, there was no significant reduction in the risk of completed rape; in the fourth, the risk of completed rape was reduced but not beyond 2 months after the intervention. ${ }^{18-21}$ The primary differences between the previous interventions and our resistance program are that ours had more hours of programming, a greater number of interactive and practice exercises, less focus on "assertive communication" and more on escalation of resistance in response to a perpetrator's perseverance, and the addition of positive sexuality content (Unit 4). ${ }^{22}$ Further research is warranted to identify the elements that are critical for efficacy so that a shorter version of the resistance program can be developed that will encourage wider implementation.

In addition to a reduction in the risk of completed rape, the 1-year risks of attempted rape, attempted coercion, and nonconsensual sexual contact were also significantly lower in the resistance group than in the control group. Data on the benefit of a sexual assault resistance program with respect to this broader range of sexual violence are scarce, and rarely have sexual contact, coercion, and attempted rape been analyzed as separate categories in the analysis. Because women cannot control men's perpetration behavior, the reductions in the risks of attempted rape and coercion and unwanted sexual con- 
tact suggest that the resistance program may have increased women's ability to detect and interrupt men's behavior at an early stage.

In contrast to the four other outcomes evaluated, the risk of sexual coercion was not significantly reduced in the resistance group. We did not collect information on the context in which attempted and completed coercion took place. Most attempted and completed rapes are committed by men who are in female students' social environment (acquaintances and classmates), ${ }^{1}$ whereas sexual coercion occurs more frequently in longer-term sexual relationships. ${ }^{37}$ It is possible that the discrepant results are explained in part by differences in the relationships in question. The resistance program focused on male acquaintances and new or early intimate relationships, to reflect the limited relationship history of first-year students. Despite this, the risk of sexual coercion was high among this cohort, which suggests that adding more education related to resisting coercion in relationships may be valuable. ${ }^{38}$

Few health-behavior prevention programs show a clear and sustained effect, and when they do, booster sessions are usually required. ${ }^{39}$ In the current trial, efficacy was shown and sustained to 1 year without booster sessions. This is important, because the risk of sexual assault is highest in the early years of university. Follow-up of trial participants is continuing to evaluate whether the benefit persists beyond 1 year.

Our trial had a few limitations. First, the resistance program is designed for women; effective interventions focusing on men's behavior are also needed. Second, by necessity, the design was open-label and the outcomes self-reported, and both of these design elements can introduce bias. Differential reporting between the groups is possible. Women in the resistance group might have underreported sexual assaults (perhaps believing that they should have been able to resist them); however, it is also possible that reporting of outcomes would be increased in women sensitized to sexual assault by the resistance training. Third, the rate of prior victimization among women who were enrolled in the study was higher than the rates generally reported in studies involving a random sample of participants. ${ }^{4}$ This was anticipated and was minimized by recruiting through psychology courses

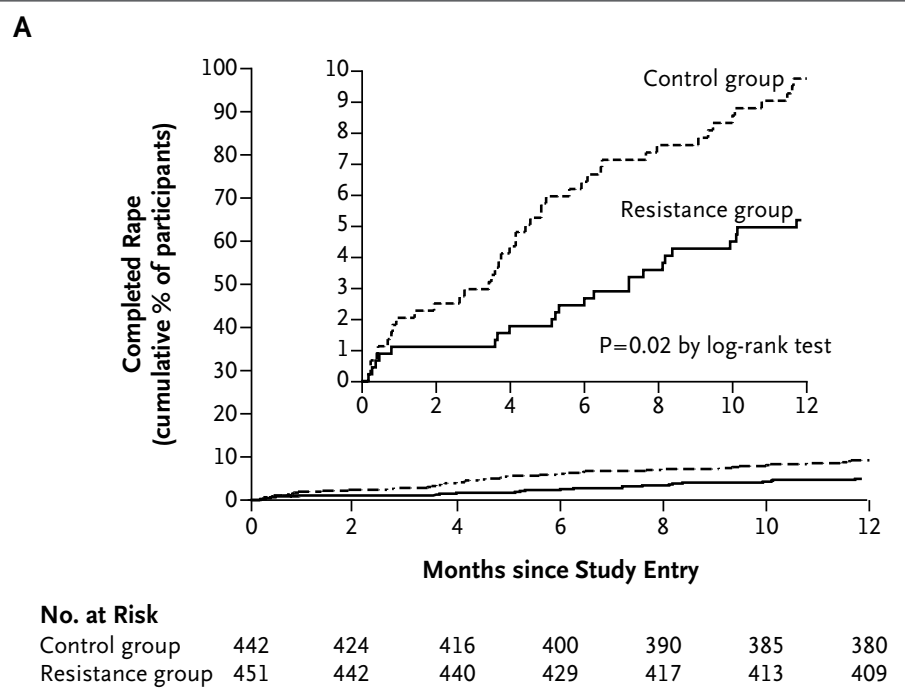

B

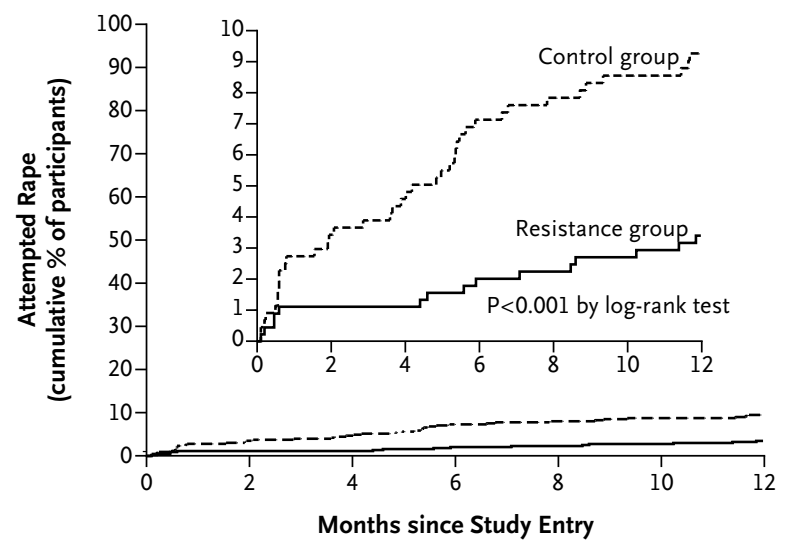

No. at Risk

$\begin{array}{llllllll}\text { Control group } & 442 & 420 & 415 & 397 & 389 & 385 & 382 \\ \text { Resistance group } & 451 & 441 & 441 & 432 & 423 & 421 & 417\end{array}$

Figure 2. Kaplan-Meier Failure Curves for Completed Rape and Attempted Rape.

The curves show the cumulative percentage of completed rapes (Panel A) and attempted rapes (Panel B) among women in the control group and those in the resistance group during 1 year of follow-up. The insets show the same data on an enlarged $y$ axis. P values calculated with the adjusted log-rank test accounted for the correlation among observations within group sessions (i.e., within-session clustering).

that offered rewards for participation. Reductions in risk were observed among women with prior victimization and among those without prior victimization. Finally, because universities may not have the resources needed to provide incentives and multiple reminders that were used to encourage participation and maximize 
Table 3. Subgroup Analyses of the 1-Year Risk of Completed Rape, According to Study Group.*

\begin{tabular}{|c|c|c|c|c|c|c|}
\hline \multirow[t]{2}{*}{ Subgroup } & Control Group & Resistance Group & $\begin{array}{l}\text { Absolute Risk } \\
\text { Reduction }\end{array}$ & $\begin{array}{l}\text { Relative Risk } \\
\text { Reduction }\end{array}$ & $\begin{array}{l}\text { Number } \\
\text { Needed to } \\
\text { Educate }{ }^{\dagger}\end{array}$ & $\begin{array}{l}\text { P Value for } \\
\text { Interaction } \%\end{array}$ \\
\hline & \multicolumn{2}{|c|}{ no./total no. (\%) } & $\begin{array}{l}\text { percentage points } \\
\quad(95 \% \mathrm{Cl})\end{array}$ & $\%(95 \% \mathrm{Cl})$ & & \\
\hline $\begin{array}{l}\text { History of completed rape since } \\
14 \mathrm{yr} \text { of age }\end{array}$ & & & & & & 0.13 \\
\hline No & $19 / 337(5.8)$ & $6 / 348(1.8)$ & $\begin{array}{c}4.0 \\
(0.9 \text { to } 7.1)\end{array}$ & $\begin{array}{c}69.4 \\
(18.0 \text { to } 88.6)\end{array}$ & 25 & \\
\hline Yes & $23 / 105(22.8)$ & $17 / 103(17.1)$ & $\begin{array}{c}5.7 \\
(-5.9 \text { to } 17.3)\end{array}$ & $\begin{array}{c}25.1 \\
(-35.3 \text { to } 58.5)\end{array}$ & 18 & \\
\hline Program timing & & & & & & 0.32 \\
\hline Weekend sessions & $14 / 151$ (9.6) & $5 / 165(3.1)$ & $\begin{array}{c}6.5 \\
(0.5 \text { to } 12.5)\end{array}$ & $\begin{array}{c}67.7 \\
(3.7 \text { to } 89.2)\end{array}$ & 15 & \\
\hline Weekday sessions & 28/291 (9.8) & $18 / 286(6.5)$ & $\begin{array}{c}3.3 \\
(-1.8 \text { to } 8.5)\end{array}$ & $\begin{array}{c}34.0 \\
(-26.5 \text { to } 65.6)\end{array}$ & 30 & \\
\hline
\end{tabular}

* Risk estimates, absolute risk reductions, and relative risk reductions were calculated from Kaplan-Meier failure curves, with variance inflation for within-session clustering.

$\dagger$ The number needed to educate was the number of women who would need to participate in the resistance program to prevent one additional completed rape from occurring within 1 year after participation. It was calculated as $1 \div$ absolute risk reduction expressed as a decimal.

$\Varangle P$ values for interaction were calculated from a Cox proportional-hazards regression model, with variance inflation for within-session clustering.

program attendance, it is unclear whether similar adherence rates can be achieved in other settings.

In conclusion, this trial showed that a rigorously designed and executed sexual assault resistance program was successful in substantially reducing the occurrence of sexual assaults among first-year female university students, including those at higher risk because of previous rape victimization.

Supported by an Operating Grant (FRN \#110976) from the Canadian Institutes of Health Research and by the University of Windsor.

Disclosure forms provided by the authors are available with the full text of this article at NEJM.org.

We thank our research assistants, program facilitators, and the rest of the Sexual Assault Resistance Education (SARE) Trial team for their help with this project.
REFERENCES

1. Fisher B, Cullen F, Turner M. The sexual victimization of college women: findings from two national-level studies. Washington, DC: National Institute of Justice and Bureau of Justice Statistics, 2000 (https://www.ncjrs.gov/pdffiles1/nij/ 182369.pdf)

2. DeKeseredy WS, Kelly K. The incidence and prevalence of women abuse in Canadian university and college dating relationships. Can J Sociol 1993;18:137-59.

3. Kimble M, Neacsiu AD, Flack WFJ Jr, Horner J. Risk of unwanted sex for college women: evidence for a red zone. J Am Coll Health 2008;57:331-8.

4. Senn CY, Eliasziw M, Barata PC, et al. Sexual violence in the lives of first-year university women in Canada: no improvements in the 21st century. BMC Womens Health 2014;14:135.

5. Brener ND, McMahon PM, Warren $\mathrm{CW}$, Douglas KA. Forced sexual inter- course and associated health risk behaviors among female college students in the United States. J Consult Clin Psychol 1999;67:252-9.

6. Koss MP, Heise L, Russo NF. The global health burden of rape. Psychol Women Q 1994;18:509-37.

7. McInturff $\mathrm{K}$. The gap in the gender gap: violence against women in Canada. Ottawa: Canadian Centre for Policy Alternatives, 2013 (https://www.policyalternatives .ca/publications/reports/gap-gender-gap). 8. The White House Council on Women and Girls. Rape and sexual assault: a renewed call to action. Washington, DC: Office of the Vice President, 2014 (https:// www.whitehouse.gov/sites/default/files/ docs/sexual_assault_report_1-21-14.pdf). 9. Violence Against Women Reauthorization Act of 2013. [S. 47] 42 USC 13701. 10. White House Task Force to Protect Students from Sexual Assault. Not alone: together against sexual assault. 2014 (https://www.notalone.gov).

11. Ontario Women's Directorate. Developing a response to sexual violence: a resource guide for Ontario's colleges and universities. Toronto: Ministry of Training, Colleges and Universities, 2013.

12. Morrison S, Hardison J, Mathew A, O'Neil J. An evidence-based review of sexual assault preventive intervention programs: technical report. Report No. 207262. Washington, DC: United States Department of Justice, 2004.

13. Lonsway KA, Banyard VL, Berkowitz $\mathrm{AD}$, et al. Rape prevention and risk reduction: review of the research literature for practitioners. Harrisburg, PA: VAWnet, January 2009 (http://www.vawnet.org/assoc_ files_vawnet/ar_rapeprevention.pdf).

14. Banyard VL, Plante EG, Moynihan MM. Sexual violence prevention through bystander education: an experimental evalua- 
tion. J Community Psychol 2007;35:463-81. 15. Gidycz CA, Orchowski LM, Berkowitz AD. Preventing sexual aggression among college men: an evaluation of a social norms and bystander intervention program. Violence Against Women 2011;17: 720-42.

16. Tharp AT, DeGue S, Lang K, et al. Commentary on Foubert, Godin, \& Tatum (2010): the evolution of sexual violence prevention and the urgency for effectiveness. J Interpers Violence 2011;26:3383-92. 17. Hanson KA, Gidycz CA. Evaluation of a sexual assault prevention program. J Consult Clin Psychol 1993;61:1046-52.

18. Orchowski LM, Gidycz CA, Raffle $\mathrm{H}$. Evaluation of a sexual assault risk reduction and self-defense program: a prospective analysis of a revised protocol. Psychol Women Q 2008;32:204-18.

19. Hanson Breitenbecher K, Gidycz CA An empirical evaluation of a program designed to reduce the risk of multiple sexual victimization. J Interpers Violence 1998; 13:472-88.

20. Gidycz CA, Lynn SJ, Rich CL, et al. The evaluation of a sexual assault risk reduction program: a multisite investigation. J Consult Clin Psychol 2001;69:1073-8.

21. Gidycz CA, Rich CL, Orchowski L, King C, Miller AK. The evaluation of a sexual assault self-defense and risk-reduction program for college women: a prospective study. Psychol Women Q 2006, 30:173-86.

22. Senn CY, Eliasziw M, Barata PC, et al. Sexual assault resistance education for university women: study protocol for a randomized controlled trial (SARE trial). BMC Womens Health 2013;13:25.

23. Senn CY, Gee SS, Thake J. Emancipatory sexuality education and sexual assault resistance: does the former enhance the latter? Psychol Women Q 2011;35:7291.

24. Senn CY, Saunders K, Gee S. Walking the tightrope: providing sexual assault resistance education for university women without victim blame. In: Arcand S, Damant D, Gravel S, Harper E, eds. Violences faites aux femmes in the collection: problemes sociaux et interventions sociales. Quebec City, Canada: Les Presses de Université du Québec, 2008:353-72.

25. Rozee PD, Koss MP. Rape: a century of resistance. Psychol Women Q 2001;25: 295-311.

26. Ullman SE. Review and critique of empirical studies of rape avoidance. Crim Justice Behav 1997;24:177-204.

27. Nurius PS, Norris J. A cognitive ecological model of women's response to male sexual coercion in dating. J Psychol Human Sex 1996;8:117-39.

28. Goldfarb ES, Casparian EM. Our Whole Lives: sexuality education for grades 10-12. Boston: Unitarian Universalist Association, 2000.

29. Kimball RS. Our Whole Lives: sexuality for adults. Boston: Unitarian Universalist Association, 2000.

30. Wen-Do Women's Self Defence home page (http://www.wendo.ca).

31. Koss MP, Abbey A, Campbell R, et al. Revising the SES: a collaborative process to improve assessment of sexual aggres- sion and victimization. Psychol Women Q 2007;31:357-70.

32. Koss MP, Oros CJ. Sexual Experiences Survey: a research instrument investigating sexual aggression and victimization. J Consult Clin Psychol 1982;50:455-7.

33. Testa M, VanZile-Tamsen C, Livingston JA, Koss MP. Assessing women's experiences of sexual aggression using the sexual experiences survey: evidence for validity and implications for research. Psychol Women Q 2004;28:256-65.

34. Stedman MR, Gagnon DR, Lew RA, Jung SH, Losina E, Brookhart MA. A SAS macro for a clustered logrank test. Comput Methods Programs Biomed 2011;104: 266-70.

35. Prentice RL, Gloeckler LA. Regression analysis of grouped survival data with application to breast cancer data. Biometrics 1978;34:57-67.

36. Rao JN, Scott AJ. A simple method for the analysis of clustered binary data. Biometrics 1992;48:577-85.

37. Basile KC. Prevalence of wife rape and other intimate partner sexual coercion in a nationally representative sample of women. Violence Vict 2002;17:511-24.

38. Fisher BS, Daigle LE, Cullen FT, Santana SA. Assessing the efficacy of the protective action-completion nexus for sexual victimizations. Violence Vict 2007;22: 18-42.

39. Nation $M$, Crusto $C$, Wandersman A, et al. What works in prevention: principles of effective prevention programs. Am Psychol 2003;58:449-56.

Copyright $\odot 2015$ Massachusetts Medical Society.

AN NEJM APP FOR IPHONE

The NEJM Image Challenge app brings a popular online feature to the smartphone.

Optimized for viewing on the iPhone and iPod Touch, the Image Challenge app lets you test your diagnostic skills anytime, anywhere. The Image Challenge app randomly selects from 300 challenging clinical photos published in NEJM, with a new image added each week. View an image, choose your answer, get immediate feedback, and see how others answered.

The Image Challenge app is available at the iTunes App Store. 